\title{
Os bastidores da tribuna: mulher, política e poder no Maranhão*
}

\section{Maria Chaves Jardim**}

O livro de Mary Ferreira, publicado pela Universidade Federal do Maranhão e que traz o prefácio da socióloga Lucila Scavone (UNESP), trata de um tema ainda pouco explorado na literatura brasileira, que é o da representação e da atuação das mulheres na política institucional e no parlamento.

Tendo como inspiração Foucault e Bourdieu, a autora nos faz refletir sobre os argumentos do pensamento "substancialista", os quais não permitem que se reconheça que a oposição entre dominantes e dominados estão em constantes mudanças, dependendo do lugar e do espaço social no qual o fenômeno é analisado.

Em termos conceituais, Foucault foi importante para a análise dos discursos das parlementares, considerando que a formulação do discurso exige ritual e qualificação dos indivíduos, para que possam ser efetivamente ouvidos e referenciados; da mesma forma, a autora inspirou-se na sua discussão sobre a forma como as relações de poder são produzidas e reproduzidas nos discursos e nas práticas das parlamentares, o que, em certa medida, leva a invisibilidade das mulheres no Legislativo. Por outro lado, o conceito de "campo", de Pierre Bourdieu, foi importante para analisar a Assembleia Legislativa do Maranhão como um campo do poder, onde homens e mulheres fazem usos de trunfos/capitais acumulados em suas batalhas cotidianas,

\footnotetext{
" Resenha de FerreIRA, Mary. Os Bastidores da Tribuna: Mulher, Política e Poder no Maranhão. São Luís-MA, Edufma, 2010. Recebida para publicação em 16 de dezembro de 2011, aceita em 29 de agosto de 2012.

** Professora de Sociologia no Departamento de Sociologia da Unesp de Araraquara.majardim@yahoo.com.br
}

cadernos pagu (41), julho-dezembro de 2013:443-448. 
visando à produção de "verdades" e de consensos. Fez uso, também, do conceito de violência simbólica desse autor, para nos fazer pensar sobre uma forma de violência presente no cotidiano do Legislativo, que é doce, e conta com a cumplicidade do dominado.

Em termos metodológicos, a autora apresenta uma rica pesquisa de campo sobre as Deputadas do Maranhão e de Portugal, cuja pesquisa se apoia na técnica de trajetória de vida dos sujeitos estudados. Já pela técnica de pesquisa selecionada por Mary Ferreira, entendemos que a autora não se interessa por abstrações macros e teóricas. Mais do que isso, ela quer identificar os sujeitos concretos (mulheres) no seu cotidiano microssociológico, compreendendo sua origem social, sua relação com a política, sua formação, os recursos (ou capitais) que disponibiliza, sua agenda de projetos mobilizados, sua sensibilidade política, sua construção discursiva, seus aliados, seus opositores e os espaços sociais que ocupam.

Ainda sobre o marco metodológico, entendemos que a opção por estudar (e até comparar) situações tão distintas (e díspares) em escalas geográficas, sociais e culturais, ou seja, parlamentares que atuam em um estado da Federação Brasileira (Maranhão), com as parlamentares de um país europeu (Portugal), deu-se por conta da trajetória pessoal da pesquisadora: moradora $e$ militante da causa "feminina" no Maranhão, realizou parte do seu doutorado em Portugal (doutorado sanduíche Capes), no centro de pesquisa liderado por Boaventura de Sousa Santos. Esse contexto possibilitou certa aproximação empírica com as parlamentares portuguesas, cujos dados foram utilizados no seu livro, bem verdade, que de forma tímida e bem pouco explorados.

Portanto, com a constatação inicial de que houve aumento significativo de presença feminina no Legislativo, tanto no Brasil, quanto em Portugal, mas que essa mudança não tem consubstanciado em mudanças estruturais nas relações de gênero, a autora busca avaliar a participação das mulheres nos espaços de poder, em particular no Legislativo, além de analisar de que forma 
a ação feminina é prejudicada, à medida que são analisadas as relações desiguais no número de cadeira ocupada por mulheres.

Seus dados indicam que o cenário do poder (sobretudo no Estado do Maranhão, mas não somente) ainda é dominado por homens, brancos, com formação superior e de origem social média ou rica. Nesse sentido, pobres, negros $e$ mulheres formariam a exceção nesse espaço social. Sua constatação dialoga com os dados de nossas pesquisas (Jardim, 2009) sobre os gestores do mercado financeiro. Nela, identificamos que negros(a), mulheres, índios(a) e pessoas de origem popular estão excluídos ou parcialmente excluídos. Da mesma forma, as poucas mulheres encontradas incorporam a violência simbólica produzida pelo campo financeiro e passam a reproduzir as crenças dos engajados nesse espaço. Intitulamos os gestores do mercado financeiro como "elite", já que são capazes de criar a doxa (senso comum). Parecenos que o campo político estudado por Mary Ferreira, também possui uma "elite" que trabalha para a manutenção e a reprodução de suas crenças, com a entrada de filhos, netos $e$ afilhados no cenário político e a exclusão daqueles que não compartilham do mesmo "mito de origem", no caso estudado, as mulheres.

Para Mary, a ausência das mulheres nos espaços decisórios, coloca em cheque a tão propalada democracia liberal. É nesse momento do texto que a autora aborda o debate das cotas, polemizando sobre os seus limites e avanços. Para a autora, as cotas tendem a ser compreendidas como um novo conceito de democracia, ou seja, de democracia paritária, que expressa o novo paradigma político e garante a paridade e a participação de indivíduos historicamente excluídos.

Sem se contentar com respostas prontas, Mary Ferreira questiona os sentidos políticos das cotas e conclui: mesmo que as cotas não garantam às mulheres real acesso ao poder, esse dispositivo traduz o reconhecimento das desigualdades de gênero, da exclusão histórica das mulheres. Portanto, trata-se de uma importante estratégia, já que, antes de tudo, revela discursos 
historicamente eufemizados pela dominação masculina e pela violência simbólica dela resultante.

De outra parte, o trabalho empírico de Mary Ferreira nos fornece elementos concretos para a atualização do debate em torno da questão de gênero. Por isso, é importante ficar atento aos dados que a autora levanta:

- sobre a inserção das mulheres no espaço político, a autora destaca três formas: laços familiares, militância política ou destaque em suas atividades profissionais. O canal familiar é visto pela autora como o mais evidente;

- sobre a produtividade das Deputadas, a autora nota que as mulheres apresentam, em termos proporcionais, maior número de projeto que os Deputados (11,54\% a mais);

- sobre o perfil dos projetos apresentados pelas Deputadas, a autora argumenta que tais projetos não diferem, no geral, dos projetos apresentados pelos Deputados. No entanto, há entre eles uma distinção de natureza e alcance, bem como da preocupação de gênero em alguns deles. A autora acrescenta que as parlamentares reconhecem as desigualdades de gênero, na medida em que seus projetos representam ações que procuram invertê-las. $\mathrm{O}$ projeto sobre microcrédito, citado pela autora, é um exemplo concreto nessa direção.

Em diálogo com seus dados e com os conceitos de Foucault e Bourdieu (2007), Mary Ferreira foge de leituras que colocam as relações de poder como relações fixas, isoladas e unilaterais. Para Ferreiras, as relações de poder são complexas, relativas, recíprocas, mediadas pela sedução, pelo consentimento e pela violência simbólica. Portanto, mesmo sem negar os limites e as tensões para a inserção qualitativa da mulher no mundo da política, bem como para as suas transgressões no mundo do poder, a autora nos mostra concretamente o crescimento quantitativo das mulheres nas Assembleias Legislativas, no Senado e em cargos executivos, fato que nos faz afirmar que a autora não se deixou seduzir pela opção teórica da reprodução das relações do poder, em si mesma. Ou seja, apesar de tímidas, é 
possível perceber transformações de natureza microssociológica no campo do poder analisado pela autora.

Segundo Bourdieu (2007), as transformações de uma sociedade acontecem como resultado de transformações cognitivas (culturais) nas mentes dos indivíduos (mundo subjetivo) e se expressam posteriormente nas leis, instituições, prédios, livros (mundo objetivo). Nesse sentido, a percepção do aumento quantitativo da presença de mulheres nos espaços políticos é importante, pois sinaliza que revoluções simbólicas invisíveis estão acontecendo nas categorias de pensamento da sociedade contemporânea, ou nas convenções cognitivas, mesmo que não tenham, ainda, se expressado no mundo objetivo.

Se seguirmos a observação do sociólogo Robert Merton (1968) de que todas as profecias são autorrealizantes, ou seja, que a realidade social é resultado de teorias e de profecias propaladas de forma inconsciente (e também consciente) por aqueles interessados em criar determinada "verdade", bem como por outros que nem sabe que estão "trabalhando" para criar essa realidade, devemos, como cientistas sociais, celebrar as tímidas mudanças apontadas por Ferreira, pois elas sinalizam que as peças do quebra-cabeça estão em mutação; que outras formas de rupturas e outras transgressões se desenham para as próximas gerações de mulheres. A eleição da Presidenta Dilma, em 2010, é um dado concreto e de significativo valor simbólico, já que possui eficácia nesse trabalho invisível (nas mentes) que deverá nos levará em direção a uma transformação das categorias de pensamento.

Concordamos com Ferreira que o papel da ciência é fundamental para o questionamento de ordens perpetuadas, ou, em outras palavras, das "profecias e teorias autorrealizantes", produzidas e reproduzidas pela sociedade. Portanto, livros como o dela cumpre o papel de ajudar na desnaturalização de doxas enraizadas na sociedade. Nas palavras da autora

os estudos feministas têm operado mudanças substanciais na ciência: ao inverter ordens estabelecidas, opondo-se as 
Os bastidores da tribuna

relações de dominação que visam perpetuar a ordem cientifica, redimensionam as pesquisas nas ciências sociais $e$ contribuem para estabelecer um contraponto às formas tradicionais de pensar a sociedade atual (p.36).

Por tudo isso, o livro de Mary Ferreira pode ser lido por acadêmicos, por militantes e pela sociedade civil em geral, pois alcança o interesse de todos os públicos e mostra que a autora entendeu muito bem as lições de Bourdieu (2007) qual seja, que para fazer uma pesquisa rigorosa, não é necessário ser rígido consigo e com seu objeto de estudo. Apesar da militância política no tema, Mary Ferreira soube equilibrar o tom da sua argumentação. Mesmo mantendo a paixão que possui pelo tema, não se deixou seduzir por caminhos e análises fáceis. Ao contrário, manteve o senso científico, aliado à sua indiscutível sensibilidade de militante.

\section{Referências bibliográficas}

Bourdieu, Pierre. Razões Práticas. Campinas, Papirus, 2007.

JARDIM, Maria A. Chaves. Entre a solidariedade e o risco: sindicatos e fundos de pensão no governo Lula. Annablume/Fapesp, 2009.

Merton, Robert. Social Theory and Social Structure. New York, Free Press, 1968. 